\title{
Chemical Industry in the United States
}

$\mathrm{P}$ ERHAPS the most remarkable thing about the meeting of the American Chemical Society held in April last in New York, and widely heralded as the "Official Tercentenary" of American chemical industry, was the presence of more than 25 per cent of the very large membership, some 17,000, of that Society. No body in Great Britain can count on such loyal support, and it affords a fine illustration of that 'working together' spirit which is carrying the chemical industry forward, so far and so fast, in the United States. Naturally the fare provided was very varied, though by collecting the papers into appropriate groups, it was possible for those with similar interests to forgather.

The social side was well to the fore, a feature being the replacement of elaborate and costly functions by a series of breakfasts, luncheons and dinners, arranged for the alumni of the numerous universities.

The opportunity for propaganda was not missed, including on one hand addresses of a general or topical character delivered by the leaders of the industry, whilst the Press was supplied with a large amount of suitable copy portraying the popular aspect and utility of the work of the chemist. They do these things well in New York under the guidance of the veteran secretary, Mr. Charles L. Parsons, and it is probable that nothing was left undone to make the meeting a gigantic success. It is worthy of comment that all the meetings could be held in the Hotel Pennsylvania, whilst the many delegates could be housed there and in three neighbouring hotels, all connected by underground passages.

Apparently the American chemical leaders are not afraid to criticise the administration. Mr. William B. Bell, president of the American Cyanamide Company, whose theme was "Recovery-by Alchemy or Chemistry", claimed that there is too much Govern. ment planning and too much Government waste; the one sound basis of industrial planning being that of purchase and sale, or profit and loss with no political interference or domination. A director of the Du Pont Company claimed that they are on the way to establish an American synthetic rubber industry, and that this has been made possible by the experience gained in the dye industry, which in particular must be in a position to expand quickly in a national emergency to make a variety of essential organic substances.

Emphasis was also laid on the popular use and significance of vitamins, preparations containing such now having the third largest sale in the drug stores.

As a novelty, it was proclaimed that young cereal grasses cut just prior to jointing have, when dry, a biological value many times that of the common vegetables and that men and women will be eating grass in the near future.

Altogether as wide a range of subjects were discussed as must have been dealt with in that famous conversation between the Walrus and the Carpenter - "and why the sea is boiling hot and whether pigs have wings".

\section{Third International Congress of Soil Science}

$F^{\prime}$ IFTY countries were represented among the four hundred delegates who attended the Third International Congress of Soil Science held in Oxford on July 30-August 7. The occasion afforded an unrivalled opportunity for discussing the many aspects presented by every problem in soil science, but differing widely according to the geographical region in which the problem is studied. One of the most urgent needs of the science is to break down the parochial barriers which necessarily limit the views of workers confined to one climatic or physiographic region, and faced with the whole-time task of economically justifying their existence. That parochialism exists was amply evident at the Congress, as also were the difficulties of overcoming it; but it was equally evident that the holding of an international congress is a practicable means of producing some kind of order among the conflicting theories held by the world's most eminent pedologists.

The discussions brought into prominence several new directions in which this young science is developing. In the Soil Physies Section, the main interest centred round problems of soil moisture, and Dr. R. K. Schofield introduced a ' $p \mathrm{~F}$ ' scale which precisely specifies the degree of wetness or dryness of a soil in much the same way that Sørensen's $p H$ scale specifies the degree of acidity or alkalinity. The $p \mathrm{~F}$ is the (positive) logarithm of the amount by which the free energy of the water in the soil is less than that of water in bulk at the same temperature and external pressure expressed as the height in centimetres of a water column. $1 \mathrm{~cm}$. above a free water table is, therefore, $p \mathrm{~F} 0$ while the 'oven dry' state is approximately $p \mathrm{~F} 7$. The use of this scale enables a great mass of hitherto unrelated data to be welded together to make an orderly picture of aspects of soil moisture behaviour which are of special importance in irrigation. Dr. Schofield stressed the necessity of recognising hysteresis in the relationship of $p \mathrm{~F}$ to moisture content, which he regards as due mainly to microplastic resistance to swelling and shrinking.

In the Chemistry Section much attention was directed, as usual, towards the base-exchange properties of soil colloids, particularly from the mineralogical point of view. The structure of montmorillonite and beidellite, as proposed by Hofman, Endell and Milne, was discussed, and Dr. C. E. Marshall showed that the apparent contradictions between their structure and the chemical formulæ can easily be removed by considering the operation 